\title{
Functional Heads in the Dholuo Determiner Phrase
}

\author{
Jerry Agalo ${ }^{1}$, Jackton Otieno Midigoa ${ }^{2}$ \\ School of Information Communication and Media Studies, Rongo University, Kenya \\ School of Arts and Social Sciences, Rongo University, Kenya
}

\begin{abstract}
This paper focuses on functional heads existing in a Dholuo DP. The notion of functional heads in the extended Projection of the CP (Complementizer Phrase) has led to a new approach in the analysis of projections in syntactic theory. The objective was to identify the functional elements in the Dholuo DP, analyze the functional elements and explain their occurrence. The study used Government and Binding theory which enables us to analyze the functional heads. The study also used descriptive research design to analyze collected data. The data was collected from 40 informants aged 35 years to 50 years; which was a sample from population of Dholuo speakers living in Homa Bay County around Lake Victoria. Data collected had sentences with Dholuo DPs. The study found eleven elements commonly occurring in Dholuo DP. These elements form the structure of Dholuo DP and can be categorized as lexical and functional heads. The lexical elements identified in the Dholuo DPs are: Nouns, Adjectives, prepositional phrases and genitive phrases. The functional elements identified included: Pronouns, article affixes, demonstratives, possessives, quantifiers, numerals, and relative clauses. In Dholuo, genitive phrases have prepositions acting as possessives. Relative clauses on the other hand, contain relative word, verb, pronoun, preposition and demonstratives.
\end{abstract}

Keywords: Functional Head, Dholuo Determiner Phrase, Lexical Items, Genitive Phrases, Relative Clauses, Relational Features, Agglutination, Co-Occurrence and Functional Projection

Date of Publication: 2018-09-30

DOI: https://doi.org/10.24297/jal.v9i1.7672

ISSN: 2348-3024

Volume: 09 Issue: 01

Journal: Journal of Advances in Linguistics

Website: https://cirworld.com

This work is licensed under a Creative Commons Attribution 4.0 International License.

Website: https://cirworld.com 


\section{Introduction}

The introduction of the notion of functional heads into the extended Projection of the CP (Complementizer Phrase) in generative grammar in 1980s led to a new approach to the analysis of projections in syntactic theory. Functional heads are elements heading a projection and do not assign theta roles (Adger 2003). They add non-thematic semantics on to lexical elements but also provide positions in the structure of phrases which relate to lexical categories in various ways. Adger (2003: 3) has observed that 'these functional categories erect a syntactic skeleton above lexical categories which serves to hold together the various syntactic relations that take place in the phrase.' Therefore, functional heads create the basis for unit displacement in sentences by providing landing sites to which phrase constituents may move.

Abney (1987) has stated that the primary property of functional elements (the same case in Dholuo syntax) is that they select a unique complement, which is not plausibly either an argument or an adjunct of functional elements. Abney gives the following characteristics of functional elements: First, they are morphologically and phonologically dependent, second, they permit only complement, which is in general, not an argument (they select VP, IP and NP), third, they are usually inseparable from their complement, fourth, they constitute closed lexical classes, fifth, they lack descriptive content (they mark grammatical or relational features rather than picking out a class of objects).

Since languages of different communities have different syntactic structures, this paper based its analysis on Dholuo language to analyze its functional elements composing a DP. Dholuo is spoken as first language by 3.4 million people in Kenya according to the government census in the year 2010. It is widely spoken by communities living around Lake Victoria covering an area of about $69,480 \mathrm{~km}^{2}$. Within DP of an English language, nouns mostly precede the determiners and other modifiers which are post nominal. The modifiers can be either functional or lexical elements. The study only pays attention to functional elements. The following sentences with possessive and demonstrative illustrate some of the DP in Dholuo:

$\begin{array}{lll}\text { Dholuo } & \text { Gloss } & \text { English } \\ \text { Buge wa } & \text { Books ours } & \text { Our books } \\ \text { Od-no } & \text { House that } & \text { That house }\end{array}$

The example given 'buge wa' (Books our-Our books) is a DP since the functional head 'wa' (our) modify the noun 'buge' (books). The functional head 'wa' (our) is a possessive (first person pronoun) heading the phrase, it also shows to who the books belong. The example 'od-no' (that house) is a phrase since it has 'no' (that) heading it hence a functional head. It is a determiner under the position of a demonstrative.

The study on this paper was qualitative, functional elements were identified and described in the Dholuo DP collected from the respondents. Primary data was obtained from first speakers of Dholuo. The 40 Dholuo speakers of mixed gender at the age of 35-50 years who were believed to be highly proficient in speaking Dholuo were selected.

The population was divided into strata of homogenous and mutually exclusive groups. The study used two strata while collecting primary data. The first stratum comprised a group of respondents speaking Dholuo as their first language (males and females) from 35 to 42 years. This was composed of young Dholuo speakers perceived to be competent in Dholuo. The second stratum was that of a cohort for comparison on how the young and the old speak Dholuo. It comprised Dholuo speakers ranging from the age of 43 to50 years.

There were some data generated in this study using intuition (direct perception of truth and fact independent of any reasoning process, according to Chomsky (1977:40). Other procedures used to collect data were: Interviewing informants in order to get data needed for analysis, structured questionnaires for respondents to produce a variety of DPs. There was also recording of conversations which were later analyzed. 


\section{History of Dholuo Speakers}

Dholuo is an African language spoken by group of people called Luo. They are majorly refered to as Joluo and a singular person from the group is referred to as Jaluo. Dholuo belongs to Nilo-Saharan family of languages which is divided into six branches (Odawa 2004). One of these branches is Chan-Nile which consists of ten groups of which Nilots belong (Greenberg 1970: 85-148). Nilotic group is further subdivided into Western, Eastern and Southern branches. Dholuo is specifically spoken by Western Nilotic branch. Western Nilots are believed to have migrated from Sudan and settled in Uganda and Kenya. Approximately about 12 million people speak Dholuo related languages in Africa. Dholuo is spoken by Luo people. Dholuo is very closely related to the languages such as Acholi, Langi, Alur, Padhola spoken in Uganda and Shilluk, Annak, Nuer of Sudan. Luo began to settle in their present geographical area in western part of Kenya between 1500 A.D and 1550 A.D. It is widely spoken in Siaya, Kisumu, Homa Bay and Migori County.

\section{Dholuo Dialects}

Crystal (2010:24 - 25) refers to dialect as grammatical and vocabulary contrasts. Crystal further notes that speakers of different dialects usually have different accents or pronunciations. Dialects of the same language share a common written language though not always mutually intelligible in their spoken form. This makes it difficult for someone speaking a regional dialect to understand some regional varieties of other areas but can be linked by chain of mutual intelligibility.

Dholuo has two major regional varieties: The Trans-Yala dialect; spoken in Ugenya, Alego, Yimbo and parts of Gem. They call the road 'apaya' whereas South Nyanza dialect spoken in various locations of Migori, Homa Bay, Siaya and Kisumu call the road 'ndara.' The words 'ndara' (road) and 'apaya' (road) means different things in South Nyanza dialect. The word 'ndara' (road) means tarmac road and 'apaya' (road) though tarmac means road which have the idea of dug out stretch to act as road in South Nyanza dialect. These dialects name same items with differently pronounced words, for example a door in Trans-Yala dialect is called 'thigo' whereas in South Nyanza dialect it is called 'dhot.' There is a traditional stool which is three legged called 'orindi' in South Nyanza dialect and the same is having a different name in Trans-Yala dialect which is called 'mbero.' South Nyanza dialect calls a garden 'puodho' whereas in Trans-Yala the garden is known as 'ndalo.'

The above examples show that the two dialects in Dholuo use different lexical items to refer to the same noun. There are instances where the lexical items only differ in spelling e.g. South Nyanza dialect calls treatment ' thieth' whereas the Trans-Yala dialect calls treatment ' chieth.' The spelling varies at the initial position. The word 'chieth' however means a different thing in South Nyanza dialect. It means feaces which is euphorically referred to as 'oko' (outside). This shows phonological differences in terms of phoneme used hence the need to be specific in the context the lexical items are being used to avoid misinterpretation. The use of tone and intonation pattern of utterances will also help interpret the lexical items. This paper collected data using South Nyanza dialect which is spoken in wider geographical area and is treated as standard in Dholuo and is found in the bulk of literature books in Dholuo.

Dholuo has gone through changes due to emerging issues in the contemporary society and this has really affected South Nyanza dialect. Most items which were not there in the ancient times and have emerged in the modern times have forced Dholuo to borrow words from Kiswahili and English which have move vocabularies than Dholuo. This therefore makes Dholuo to have loan words. Technology has introduced several innovations hence introducing new items in the contemporary society. An item like a machete used for cutting did not exist in the past in luo community. Kiswahili calls it 'panga' and Dholuo has borrowed the name ever since calling it 'opanga' they insert the vowel 'o' to suit their sonorant in pronunciation of words. Since the item is used for cutting, it has also coined a name in Dholuo due to the use hence they call it 'beti' (machete). The noun 'beti' can mean slash if the last syllable is stressed hence changing the tone. This shows that meaning of words in Dholuo is also affected by how they are pronounced. This item can be used for slashing which is 'beto' (slashing) in Dholuo. It therefore suggests that Dholuo can form nouns from verbs. When the tone rises, the word 'beto' (slash) becomes infinitive verb (to slash). When it is pronounced with falling tone, it becomes a 
continuous tense where in English, there is addition of suffix '-ing' to make it a passive voice as well. An item like a dish is modern and never existed in the history of Dholuo, it has been borrowed by luo people hence they call it 'dis' (dish). Here letter ' $h$ ' is missing because sound $/ / /$ does not exist in Dholuo. Dholuo has also borrowed words from communities adjacent to their localities such as Luhya community. There is a word Luhya use in greeting which is also used by the Luo though the spelling is not one on one similar. The word is ' Murembe' (good morning) as pronounced by the Luhya. The Luo people pronounce it as 'Mirembe' (good morning) which is equivalent to 'oyaore' (good morning) directly translated in English as (it has opened). Luo people use the greeting word 'oyaore' to remind the colleagues they are greeting that it is a new dawn and that things have started a fresh. It also connotatively means wishing someone you are seeing for the first time of the day a good lack that the day carries.

\section{Phonological Characteristics of Dholuo}

Dholuo has five basic vowel phonemes (sounds that differentiate word meaning). In Dholuo, vowels are similar to English e.g. a, e, i, o, u however, some words can end in the syllable which are nasalized e.g. $\eta$ (ng') as in 'chieng' (sun). It is also possible to start a word with ' $y$ ' as in 'ywech' (broom). Mother tongue interference common in Dholuo while speaking English is noticeable in words ending with 'sh' where ' $h$ ' is avoided since 'sh' does not form words in Dholuo. An example is in a word like fish which would be pronounced as 'fis'. It has two sets of five vowels, distinguished by feature [+/-ATR] which is, advanced tongue root (meaning, the vowel is produced by pulling the root of the tongue forward to add a breathy quality to vowels).

Dholuo is a tonal language manifested in both lexical and grammatical conditions e.g. in the formation of passive verbs. This means that one lexeme can be pronounced differently to give different meaning. According to Benard, O. Florence, I and Sangai, M. (2013) on an exposition of some adapted lexemes in Dholuo, there are four distinct tones in Dholuo namely: high tone as in món (women), low tone as in 'lum' (grass), falling tone as in nyânyâ (tomato) and rising tone as in la $\mathbf{w}$ (dress). It has vowel harmony by ATR status: the vowels in the non compound word must be either all [+ATR] or all [-ATR]. The ATR-harmony requirement extends to the semi-vowels /W/, /Y/. Vowel length is contrastive. Dholuo can also be said to be vowel harmony language where harmony according to Katamba, F. (1989) is a phonological assimilation. Here vowels in a word agree in one or more features like height, being back or front, round or spread. This harmony is realized in terms of tongue root feature $[+$ ATR $]$

\section{Structure of Dholuo Language}

According to Onyango, P.O.( 2001), Dholuo has 22 basic alphabets; 17 consonants and 5 vowels. A, B, (C), E, F, $\mathrm{G}, \mathrm{H}, \mathrm{I}, \mathrm{J}, \mathrm{K}, \mathrm{L}, \mathrm{M}, \mathrm{N}, \mathrm{O}, \mathrm{P}, \mathrm{R}, \mathrm{S}, \mathrm{T}, \mathrm{U}, \mathrm{W}, \mathrm{Y}$. ' $\mathrm{C}$ ' does not stand alone so it takes ' $\mathrm{H}$ ' for its sound e.g 'chiemo' (food), 'chack' (milk) and chuodho (mud). On the other hand,'s' in Dholuo does not take ' $h$ ' to form /J/ while forming lexemes. We only have words like 'msumba' (bachelor) Dholuo is notable for its complicated phonological alternations, which is being used among other words in distinguishing inalienable possession from alienable. Alienable means that something is not part of the other. Some words in Dholuo are similar in spellings but different in meaning according to the accent e.g. the word 'kendo' can mean again when both syllable ' $k e^{\prime}$ and ' $n d o$ ' has same accent. It can mean fireplace when only ' $k e^{\prime}$ is stressed and pronounced as long sound. It can as well mean to marry if pronunciation is short.

Dholuo has a CVC or VC structure-consonant/vowel/consonant or vowel consonant in the word formations. This therefore means that Dholuo can end in a consonant e.g. 'wan' (we). From Eunita, D. (2006) on 'Selected Proceedings of the $36^{\text {th }}$ Annual Conference on African Linguistics,' we find that Dholuo is very different from English and West African languages that have a more analytic or isolating structure. Most of its clauses consist of a series of words each composed of a single morpheme e.g. in the sentence:

Dholuo

3. Onyango dhi chiro
Gloss

Onyango going market

\section{English}

'Onyango is going to the market 
' $d$ i' is a single morpheme yet when translated in English it is separated into two words as shown above, i.e. is (aux) and go (main verb). In Dholuo, the tense is realized phonologically (i.e. by tone). But in English, the auxiliary (be) changes to (is) to realize tense (i.e. present tense). From the above Dholuo sentence, we also find that the subject noun Onyango is followed immediately with the verb 'dhi' ('go'-in English). There is no pronominal subject for agreement with Onyango and the present tense is not overtly marked but marked tonally. (Present tense is not overtly marked in Dholuo)

The concept of 'possession' or 'belonging to' is expressed in two alternative but interchangeable ways with associative ' $m a r^{\prime}$ ('of'-in English) and possessive adjective suffix such as '- $a$ ' first person possessive adjective e.g. 'mara' ('mine'-in English). The associative 'mar' is used when the possessor is noun, whereby 'mar' is preceded by the possessed noun and followed by possessor noun as in:

\section{Dholuo}

4. Book mar sikul
Gloss

Book POSS-of school

'Book of school'

\section{English}

'The school's book' (English)

'Mar' can also be prefixed to a possessive pronoun suffix '- $-e^{\prime}$ ' as in:

'Child of him/her bad'
Dholuo

Gloss

Child of 3-POSS bad (Adj)

\section{English}

5. Nyathi mare rach

'His/her child is bad'

'Mar-' is preceded by possessive, 'nyathi' (child) and the third person possessive adjective suffix'- $e^{\prime}$ proceed it. Dholuo marks possession by suffixing i.e. using the suffix ' $-n e^{\prime}$. The above example 6 can also be written as:

\section{Dholuo}

6. Nyathi-ne rach

\section{Gloss}

Child his bad

\section{English}

His/her child is bad

Dholuo is an agglutinating language. Finegan (2004) defines agglutinating languages as those languages whose words can have several prefixes and suffixes that are characteristically distinct and readily segmented into their parts e.g.

\section{Dholuo}

7. A-dhi-ga chiro

8. I-dhi-ga chiemo

9. O-wuotho-ga marach
Gloss

I go do market

You go do eat

$\mathrm{He} / \mathrm{she}$ walks do badly

\section{English}

I do go to the market

You do go to eat

$\mathrm{He} /$ she walks badly

The above examples show that Dholuo has prefixes and suffixes that can be readily segmented into distinct parts. The prefix ' $a-^{-}$' in example 7 is a person marker; first person singular whose plural is the prefix ' $w a{ }^{-}$'. Second person singular is marked by prefix ' $i-$ ' as shown in example 8 and its plural ' $u$-' while third person is marked by prefix ' $O-{ }^{\prime}$ ' as shown in example 9 and the plural is ' $g-$ '. This third person marker is common to both genders in Dholuo. The prefix of third person singular has no gender marker as in English. 
Dholuo is a tonal language manifested in both lexical and grammatical conditions e.g. in the formation of passive verbs. This means that one lexeme can be pronounced differently to give different meaning. According to Benard, O. Florence, I and Sangai, M. (2013) on an exposition of some adapted lexemes in Dholuo, there are four distinct tones in Dholuo namely: high tone as in món (women), low tone as in lum (grass), falling tone as in nyânyâ (tomato) and rising tone as in la ww (dress). It has vowel harmony by ATR status: the vowels in the non compound word must be either all [+ATR] or all [-ATR]. The ATR-harmony requirement extends to the semi-vowels /w/, / /. Vowel length is contrastive. Dholuo can also be said to be vowel harmony language where harmony according to Katamba, F. (1989) is a phonological assimilation. Here vowels in a word agree in one or more features like height, being back or front, round or spread. This harmony is realized in terms of tongue root feature $[+\mathrm{ATR}]$

\section{Data Analysis}

Sentences with the Dholuo DPs were analyzed to get useful information so as to find the functional elements which were also found to be the heads of Dholuo DPs. The collected data were organized for analysis using figures under X-bar theory. The open coding was used through intuitive knowledge in identifying the underlying sentential constructions collected and were subsequently coded. Grey (2009) defines open coding as a process involving allocating an identification number to data.

\section{Data Presentation}

The study used extended x-bar theory in GB to analyze how functional elements are projected in Dholuo DPs. The theory grants functional elements a central role in Dholuo language faculty as the heads of their own projection. Thus, functional heads in Dholuo mark and head each of the basic constituents in a Dholuo sentence thus establishing the structural skeleton of these sentences. Functional categories therefore have been considered as critical in setting cross-linguistic parametric values such as word order variation (Hyams, 1986; Lebeaux, 2000) and in allowing recursion (Lust, 2006).

There are many functional heads that can occur within the DP in Dholuo. These include demonstratives which contain [+ Deictic] as well as [+Def] features, possessives with [+ poss] as well as [+Def] features, quantifiers which contain [- Def] and numerals which contain [ - Def]. Therefore, within the DP in Dholuo, these functional categories are projected as follows: DemP, PossP, QP and NumP. Articles were found to be similar to demonstratives in Dholuo DP and pronouns too were found to be similar to possessives.

\section{Demonstratives}

Adger (2003), notes that demonstratives signify how the speaker wants to direct the hearer's attention. Demonstratives signify that the speaker assumes that the hearer will be able to identify the referent point of the phrase as being close or far away, in either dispersal or discourse terms. Dholuo has pre-nominal demonstratives and post-nominal demonstratives. They have the function of 'pointing out' equivalent to deixis. Deixis is the property of certain expressions and categories (including tense) of relating things talked about to the spatio-temporal context and in particular, to contextual distinctions like that between the moment or place of utterance and other moments or places, or that between the hearer, speaker, and others (Lyons, 1999:18). Pre-nominal demonstrative identified in Dholuo DPs were: ' $m a^{\prime}$ (this), 'magi' (these) and 'mago' (those). Post- nominal demonstratives identified were: ' $n i^{\prime}$ (this), ' $g i^{\prime}$ (these), 'no' (that), 'go' (those), 'ka'. The table below shows how demonstratives in Dholuo can be utilized. Demonstratives have been italicized for easy identification. 
Table 1. Types of demonstrative in Dholuo

\begin{tabular}{|c|c|c|c|}
\hline & Near speaker & Near hearer & Away from both \\
\hline Demonstrative & $\mathbf{N i}$ (this), gi (these) & No (that), go (those) & Cha (that), ka (those) \\
\hline People & $\begin{array}{l}\text { Wuoi ni (This boy) } \\
\text { Yawuoi gi (These boys) }\end{array}$ & $\begin{array}{l}\text { Wuoi no (That boy) } \\
\text { Yawuoi go (Those boys) }\end{array}$ & $\begin{array}{l}\text { Wuoi cha (That boy) } \\
\text { Yawuoi ka (Those boys) }\end{array}$ \\
\hline Thing & $\begin{array}{l}\text { Odni (This house) } \\
\text { Udi gi (These houses) }\end{array}$ & $\begin{array}{l}\text { Odno (That house) } \\
\text { Udi go (Those houses) }\end{array}$ & $\begin{array}{l}\text { Odcha (That house) } \\
\text { Udi } \boldsymbol{k a} \text { (Those houses) }\end{array}$ \\
\hline Place & $\begin{array}{l}\text { Kaa (Here) } \\
\text { Kuondgi (These places) }\end{array}$ & $\begin{array}{l}\text { Kanyo (There) } \\
\text { Kuondego (Those places) }\end{array}$ & $\begin{array}{l}\text { Kucha (That place) } \\
\text { Kuonde } \boldsymbol{k a} \text { (Those places) }\end{array}$ \\
\hline Time & $\begin{array}{l}\text { Sani (This time/ now) } \\
\text { Sechegi (These times) }\end{array}$ & $\begin{array}{l}\text { Sano (That time) } \\
\text { Sechego (Those times) }\end{array}$ & $\begin{array}{l}\text { Sacha (That time) } \\
\text { Sechego (Those times) }\end{array}$ \\
\hline
\end{tabular}

When a demonstrative is used with nouns having more than one syllable, they stand on their own e.g. 'Wuoi ni' (this boy), 'Udi gi' (these houses) and 'Kuonde ka' (those places). Where a noun with a syllable is used, the demonstrative affix is agglutinated to the noun e.g. 'odni' (this house) and 'sani' (this time). Demonstratives in Dholuo can also be used to mark definiteness. Lambrecht (1994:79) defines definiteness as an entity which is familiar, by virtue of being present either in the physical discourse environment or in the discourse context as an entity that is identifiable to both the speaker and addressee while indefiniteness refers to an entity which the speaker assumes the addressee cannot identify. In Dholuo, demonstratives are seen to perform a dual role. An example in a sentence to show how X-bar theory project demonstrative as having $D$ category hence making a phrase to be a DP is shown in the figures below.

Where the demonstrative is post nominal, the tree diagram will appear as drawn below.

1. Wuoi ni (This boy)

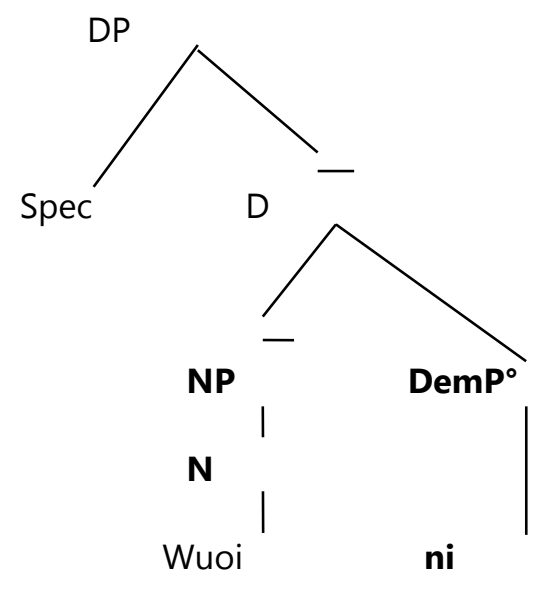

Fig. 1. Projection of demonstrative in X-bar theory

From the figure 1 above, 'ni' (this) is a functional head since it falls under the head position. The head ' $n i^{\prime}$ (this) is a demonstrative functioning as a determiner heading the Dholuo DP 'Wuoi ni' (this boy). 'Wuoi' (boy) is a lexical (noun) word acting as a complement. The above figure can have a different appearance in a case where a demonstrative is used at the initial position of the Dholuo DP. The head position will reverse to the left making the phrase to be a head initial. Here the affix used as demonstrative changes the form to ' $m a$ ' which is equivalent to a demonstrative and auxiliary verb in English (this). 
Where the demonstrative is pre-nominal, then the tree diagram will appear as follows:

2. Ma wuoi (This is a boy)

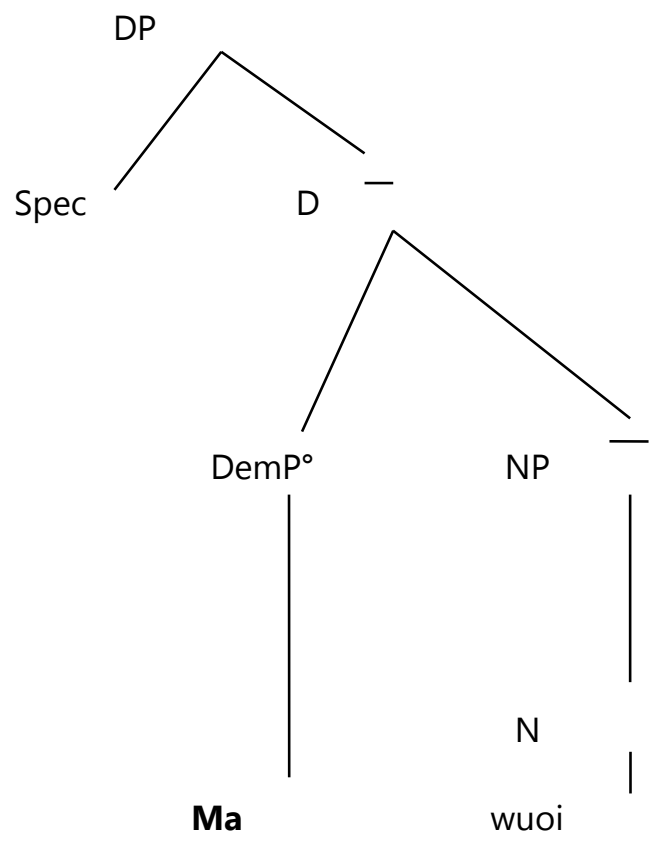

Fig. 2. A demonstrative before a noun

Considering the following example with a demonstrative (italicized) as a functional head occurring within the Dholuo DP, the study illustrates the position demonstrative takes.

\section{Dholuo}

3. Ndalo ka
Gloss

Days those

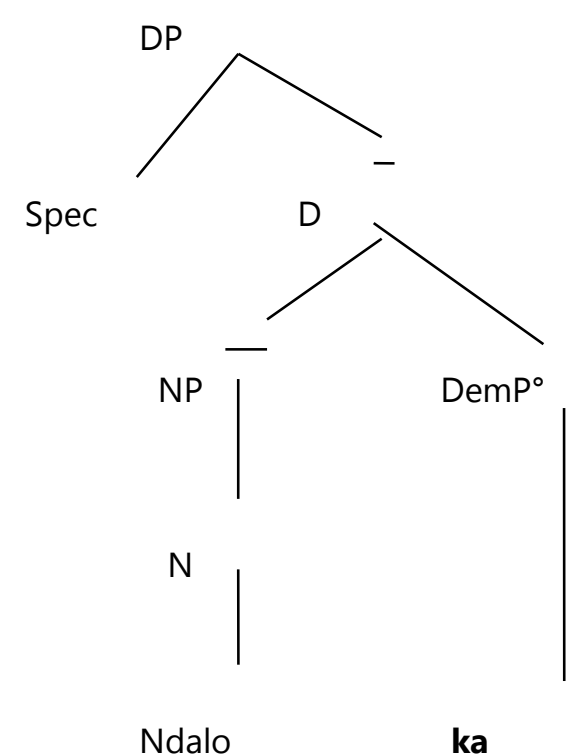

Spec

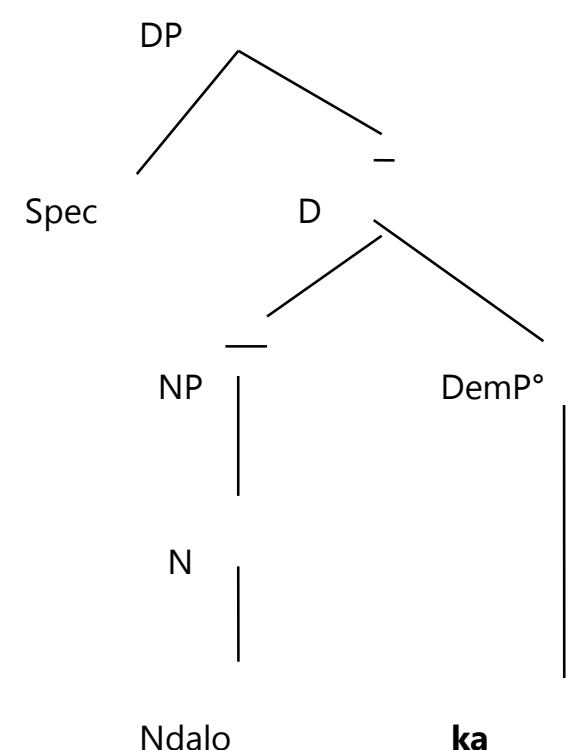

N

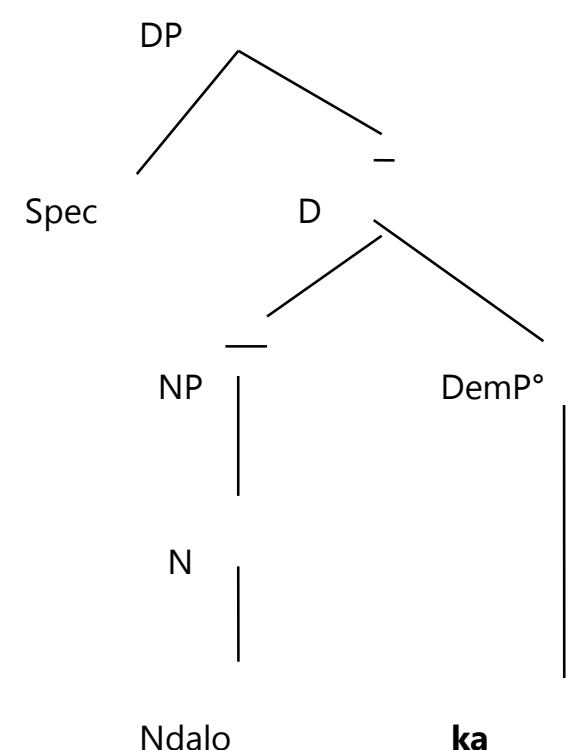

Ndalo

\section{English}

Those days

Fig.3. DP with only demonstrative as a functional head 
In the above figure, demonstrative is projected at the final position following the noun which is its complement. Demonstratives as functional categories within the DP have various base-generated positions across languages (Chang 2009).

Dholuo has both definite and indefinite article affixes, demonstratives, possessives and quantifiers that contain D-feature and can occupy the D-head position within the DP. In Dholuo DP, these elements of D-category can co-occur with each other. Where demonstrative co-occur with other functional heads post-modifying nouns in Dholuo DP, demonstratives take the final position, however demonstrative can also precede a quantifier in a Dholuo DP, e.g. 'Ndalo mang'eny te $k a^{\prime}$ (Days many all those to mean All those many days). And 'Ndalo mang'eny ka te' (Days many those all to mean All those many days). In a case where both demonstrative and quantifier are projected, either of them can precede each other. Figure 17 below shows the DP structure where demP (demonstrative phrase) precede a QP (quantitative phrase).

\section{Dholuo}

4.Ndalo mang'eny ka te

\section{Gloss}

Days many those all All those many days

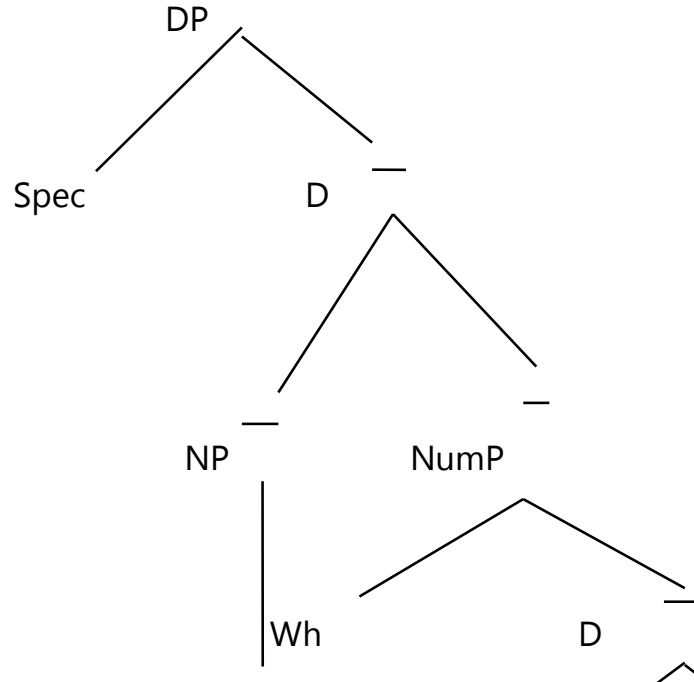

$\mathrm{N}$

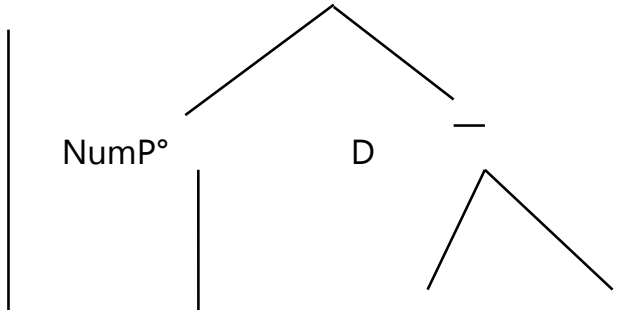

$\mathrm{DemP}^{\circ}$

$\mathrm{QP}^{\circ}$<smiles>CCO</smiles>

Ndalo ma ng'eny ka te

Fig.4. Projecting functional heads (NumP, DemP and QP)

Demonstratives in Dholuo agree with the number marking the nouns they modify, they also specify the distance between the noun in question and the hearer. Demonstratives showing the furthest distance such as 'cha' (that) in singular and ' $k a$ ' (those) in plural can be analyzed as given in the following figure: 
Dholuo

5. Ndalo mang'eny $k a$
Gloss

Days many those
English

Those many days

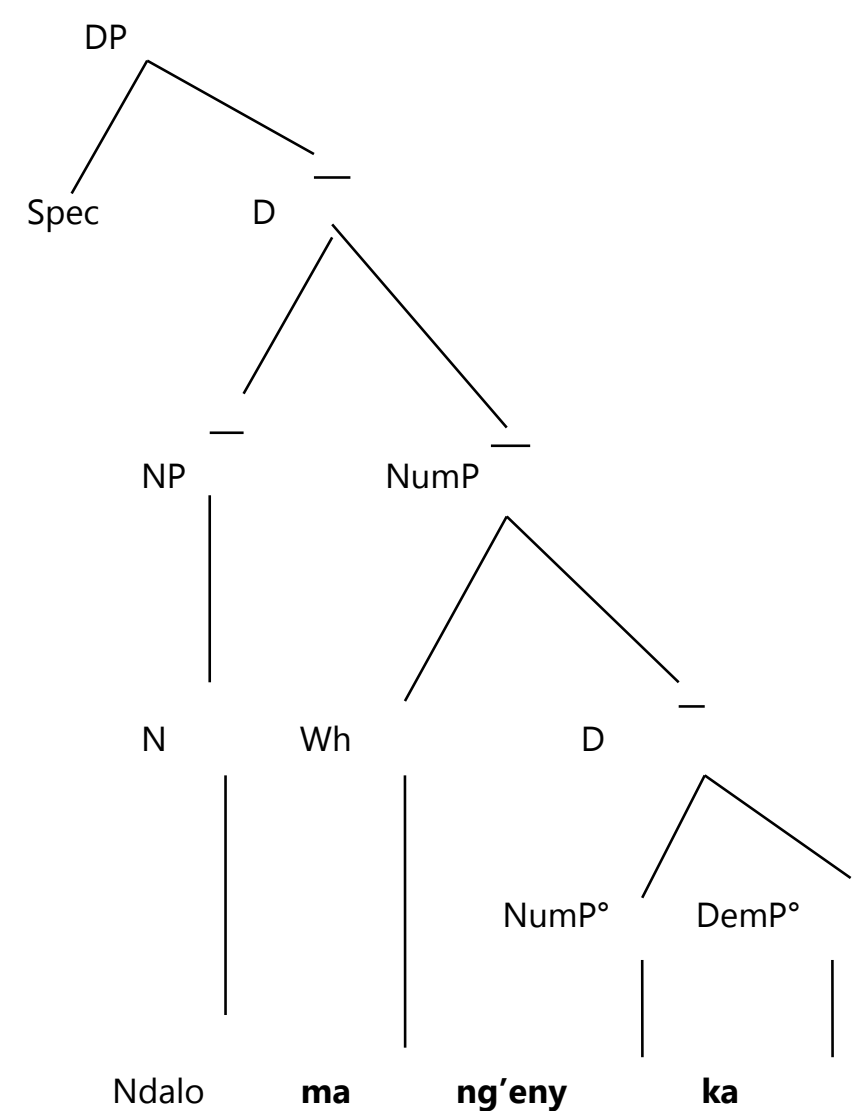

Fig. 5. Projecting NumP and DemP at the head position

In a Dholuo DP where a relative clause has been included, we will have a structure where demonstrative takes the final position. This is shown in the following figure.

\section{Dholuo}

Gloss

\section{English}

6.Ndalo mang'eny mane richo ka te Days many which were bad those all all those many days

which were bad

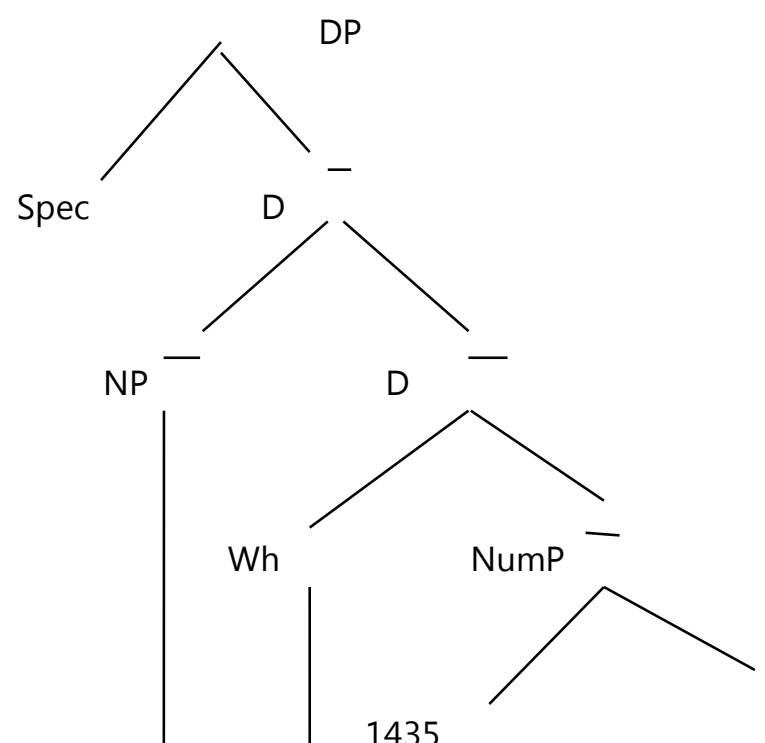




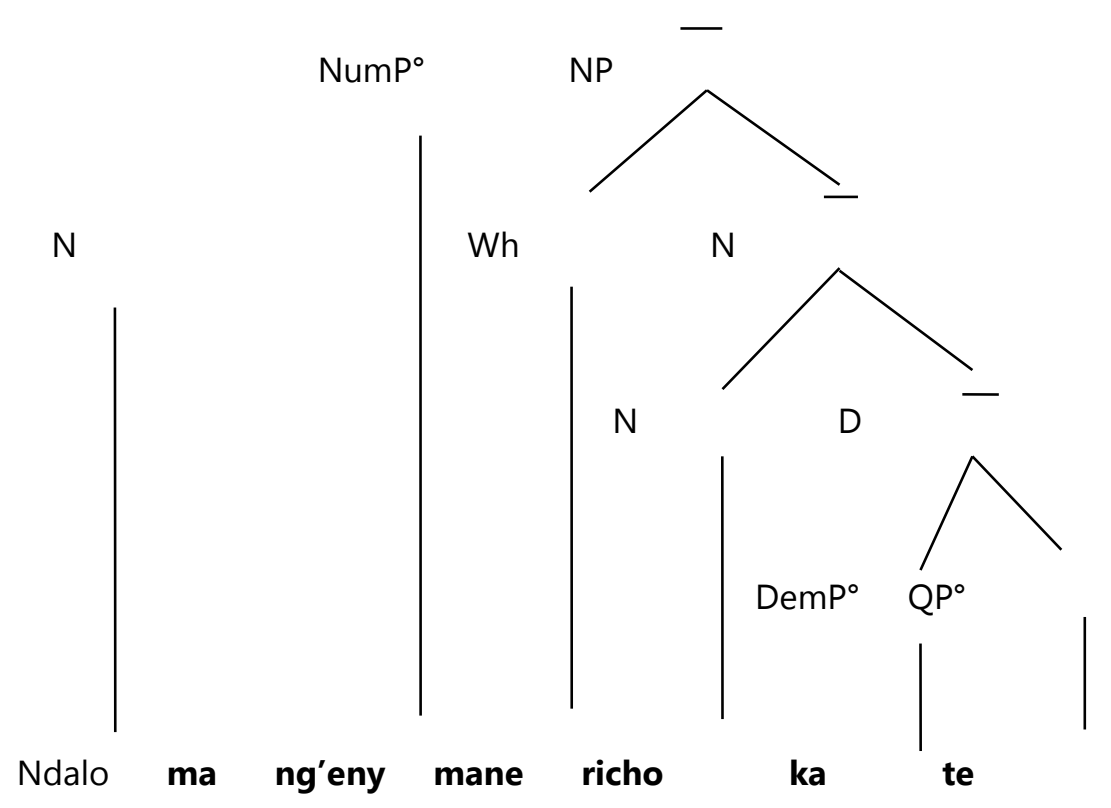

Fig. 6. showing projection of NumP, R.cl, DemP and QP

\section{Possessives}

Dawn (1997) observes that possessive pronouns and other possessive markers are functional projections which project the possD. Chang (2003), notes that possessives are generated by a possessive feature (+poss) which has to be checked before spell out. In Dholuo possessives comes immediately after nouns in a DP. Possessives identified in the Dholuo DPs were: First person possessive pronouns; ' $a$ ' (my) which is a suffix getting agglutinated with nouns possessed e.g. oda (my house). Ot (house) changes the final voiced consonant $/ t /$ into a voiced consonant $/ d /$ so as to agree with the possessive affix '-a' equivalent to (my) in English. In marking number, a consonant ' $w$ ' is added hence becoming suffix '- $w a$ ' which can either be agglutinated to nouns or stand on its own when showing possession of a possessed item with more than one syllable as shown in the examples given ( the possessives are italicized for ease of identification). 'Odwa' (our house) or 'ute $w a$ ' (our houses), we also have words that can be used in Dholuo to mark possessives like 'mara' (mine) and 'marwa' (ours), when used in conjunction with demonstratives ' $n i$ ' (this) and ' $g i$ ' (these) in a Dholuo DP. Examples showing use of these words are: 'Bugni mara' (this book is mine) and 'bugegi magwa' (these books are ours). Dholuo have auxiliary verb 'en' (is) and 'gin' (are) which can be omitted in a DP however, when included, the sentence will be; 'Bugni en mara' (this book is mine). 'Bugegi gin magwa' (these books are ours). These are presented as follows: 
7. Buga (my book)

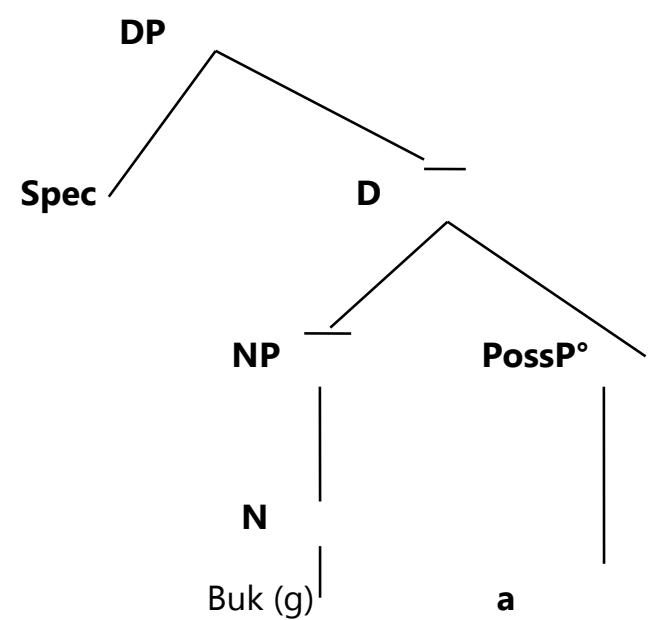

Fig. 7. Projection of a possessive in Dholuo DP

8. Bugni en mara (this book is mine)

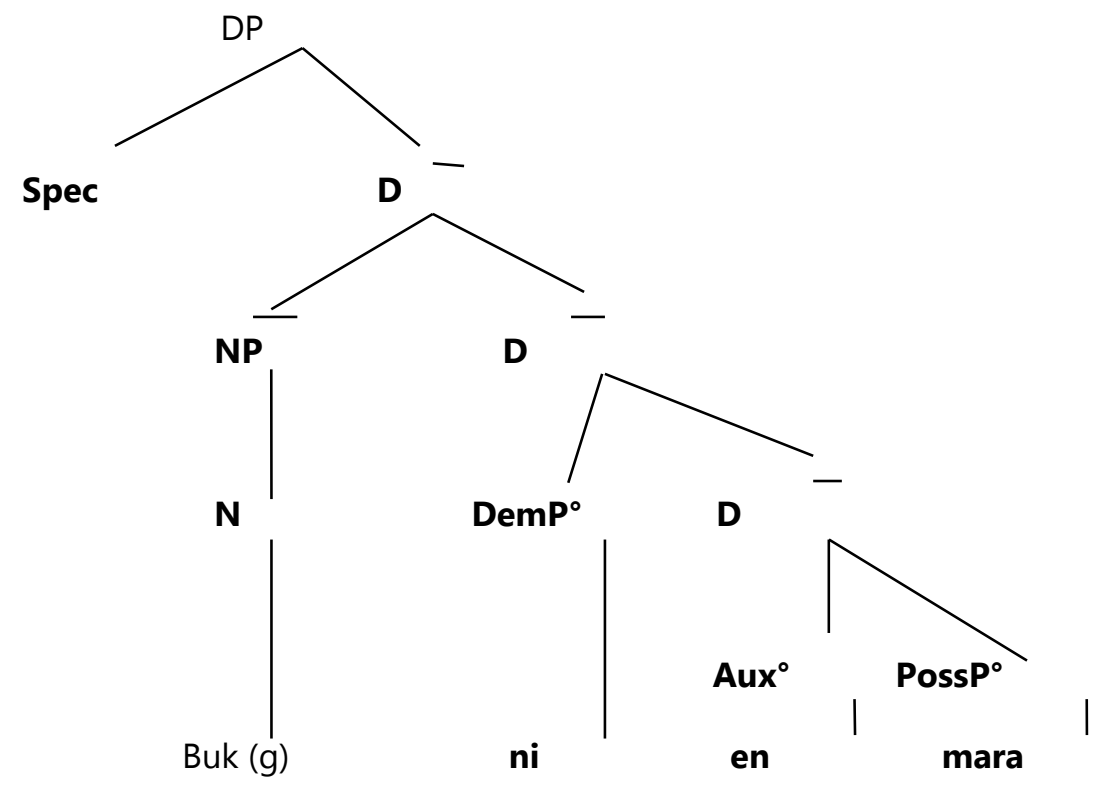

Fig. 8 Projection of possessive co-occurring with other elements as heads of DP

Some other possessives in Dholuo DPs are suffixes like: '- $i$ ' (your); an example in a sentence is, 'odi' (your house) and '- $u$ ' (your-in plural); an example in a sentence is, 'odu' (your house). These suffixes fall under second person possessive pronouns. Third person possessive pronouns in Dholuo DPs are: ' $-e^{\prime}$ (his/her/its); an example in a sentence is, 'ode' (his/her/ its house) and '-gi' (their); an example in a sentence is, 'odgi' (their house).

Possessives in Dholuo DP are elements that belong to D-category hence they occur with the other elements of the same category (definite and indefinite article affixes, possessives and quantifiers). Possessives in Dholuo project their own functional projection and this study adopted the PossP named by Adger. For Possessives in Dholuo are elements of D-category, PossP like DemP, functional projection must occur immediately below the $D$-head position and intermediate between $D$ and NumP. Where many functional categories co-occur with possessive in a Dholuo DP, Possessive is always projected immediately after the lexical element noun. Noun occurs at the position of NP acting as the complement of DP. This argument is illustrated in the example 9 below. 
Dholuo

9 Nyithindwa adek gi te
Gloss

Children our three these all
English

All these our three children

The possessive used in the above example (9) falls under first person plural. The study realized that possessives modify nouns/NPs immediately before other elements appearing in a Dholuo DP which it cooccurs with. This can be projected as given below.

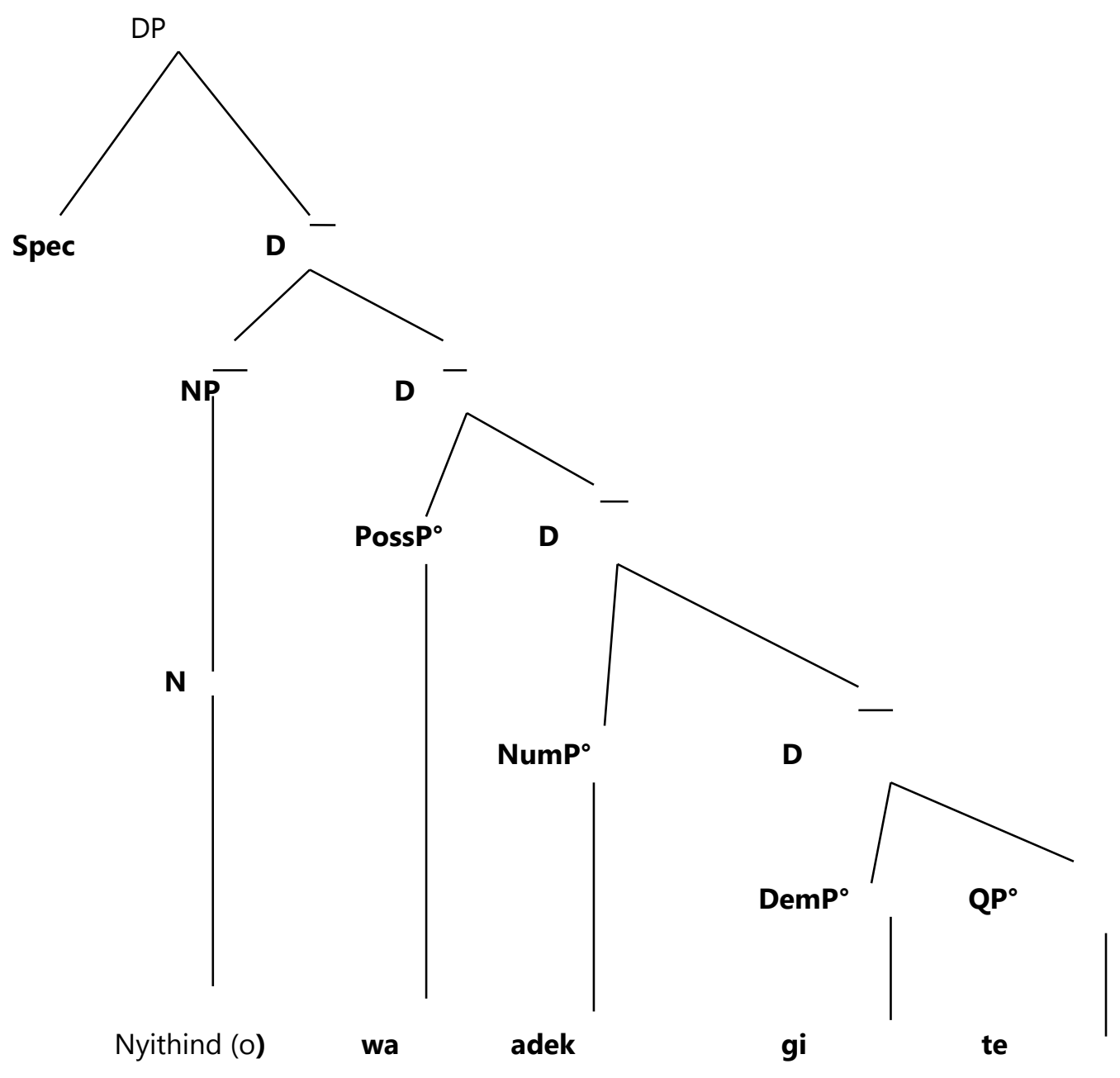

Fig. 9 Position of PossP as projected among other functional categories

\section{Quantifiers}

Radford (2004), says that quantifiers serves to quantify the noun that follows them. Radford (1994) and Valois (1991) suggest that quantifiers head a functional projection hence project a maximal projection (QP). They also state that there are still controversies as to which elements can be classified as quantifiers. This study considered cardinal and ordinal numbers as well as some quantity words like all, some any, little and much to be quantifiers. Following Radford and Valois' observation, the study identified the following quantifiers in Dholuo DP: Cardinal numerals like 'ariyo' (two), ordinal numerals like 'mokuongo' (first), 'mogik' (lastly) and quantifiers like 'matin' (little) and 'mang'eny' (many). It is possible to have both ordinal and cardinal numerals appearing in Dholuo DP e.g. Buge ariyo mokuongo (the first two books). It is not possible to have both numerals and quantifiers in a Dholuo DP except in few cases like the one in a sentence as; buge ariyo te mokuongo (all the first two books). Nevertheless, ordinal numerals can co-occur with quantifiers e.g. Buge mang'eny mokuongo ( the first many books). Dholuo deletes a syllable once it immediately precedes another 
in a word at initial position. This is because co-occurrence of two different sounds following each other in Dholuo is heavy to pronounce. Quantifiers can be projected in X-bar theory as follows.

10. Wach $\mathbf{m}$ (a)okuongo (wach mokuongo) (the first word)

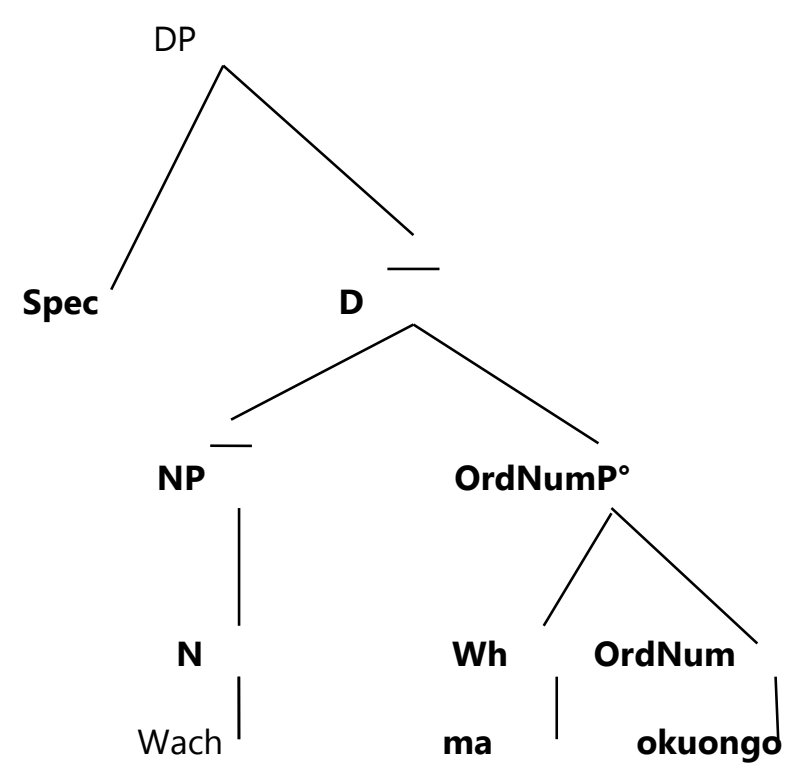

Fig. 10. Projection of ordinal numeral in X-bar theory

11. Buge ariyo $\mathbf{m}$ (a)okuongo (The first two books)

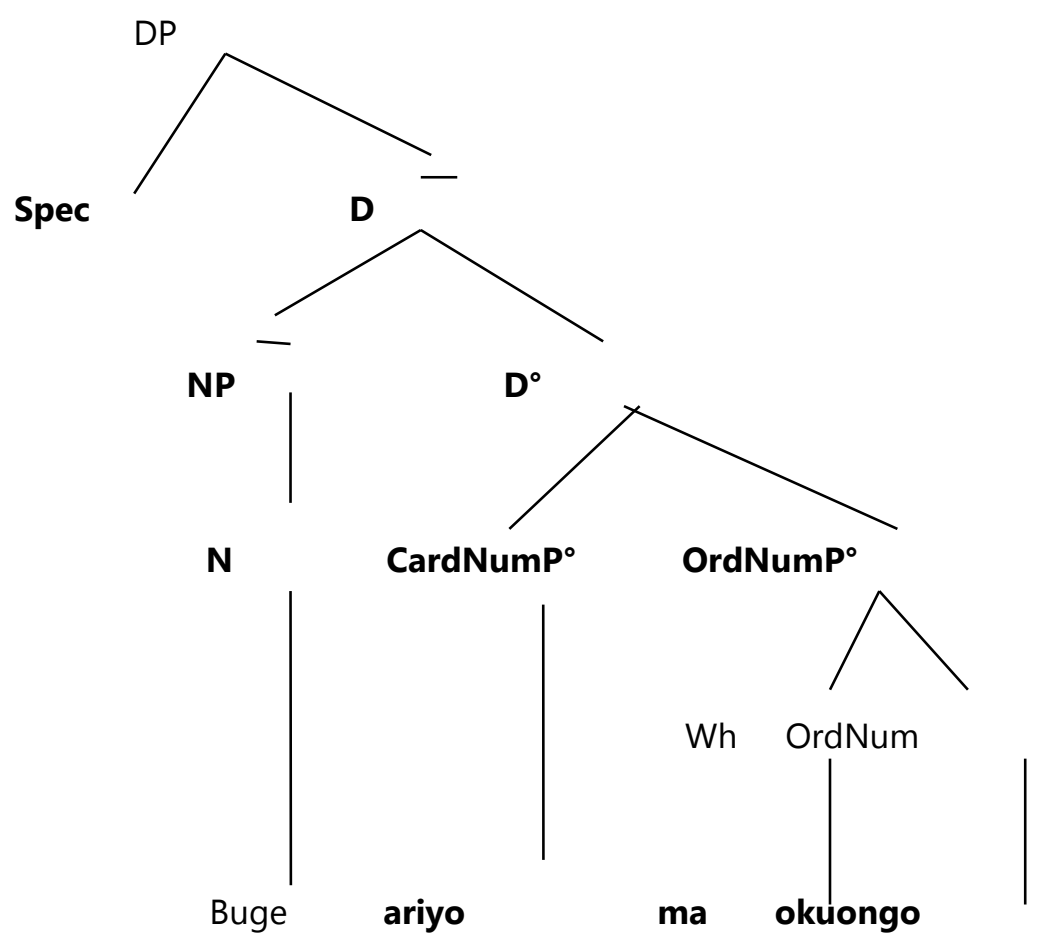

Fig. 11 projection of cardinal numeral and ordinal numeral 
In Dholuo, quantifiers are: 'matin' (little/few), 'mang'eny' (many/much and 'te' (all). Quantifiers in Dholuo contain D-features hence belonging to a group of elements in D-category. This paper treated quantifiers in Dholuo DP as functional heads of Q-category and they project their own functional projection QP. This helps to capture the co-occurrence of functional elements containing D-feature in Dholuo. QP comes after nouns/pronouns and possessives in Dholuo DP. Dholuo does not have QPs which are used specifically for countable or uncountable nouns as in English where 'much' quantify uncountable noun while 'many' quantify countable nouns.

\section{Numerals}

In Dholuo numerals such as cardinal and ordinal project their own functional projection as NumP. Numerals in Dholuo DP precede quantifiers. They are functional heads and they project their own functional projection NumP. They exist as free words, unlike possessives; they do not have affixes which can get agglutinated to any word class. Numerals are sub-divided into ordinal used in counting such as 'achiel' (one), 'ariyo' (two) and 'adek' (three). Another sub-division of numeral is cardinal which is used in ordering items or thoughts in a sequence such as 'mokuongo' (first) 'mar ariyo' (secondly) and 'mogik' (finally). In Dholuo DP ordinal and cardinal can co-occur interchangeably as shown in example 14 which shows projection of numerals.

\section{Dholuo}

14. Weche ariyo mokuongo

Weche mokuongo ariyo
Gloss

Words two first

Words first two

\section{English}

The first two words

The first two word

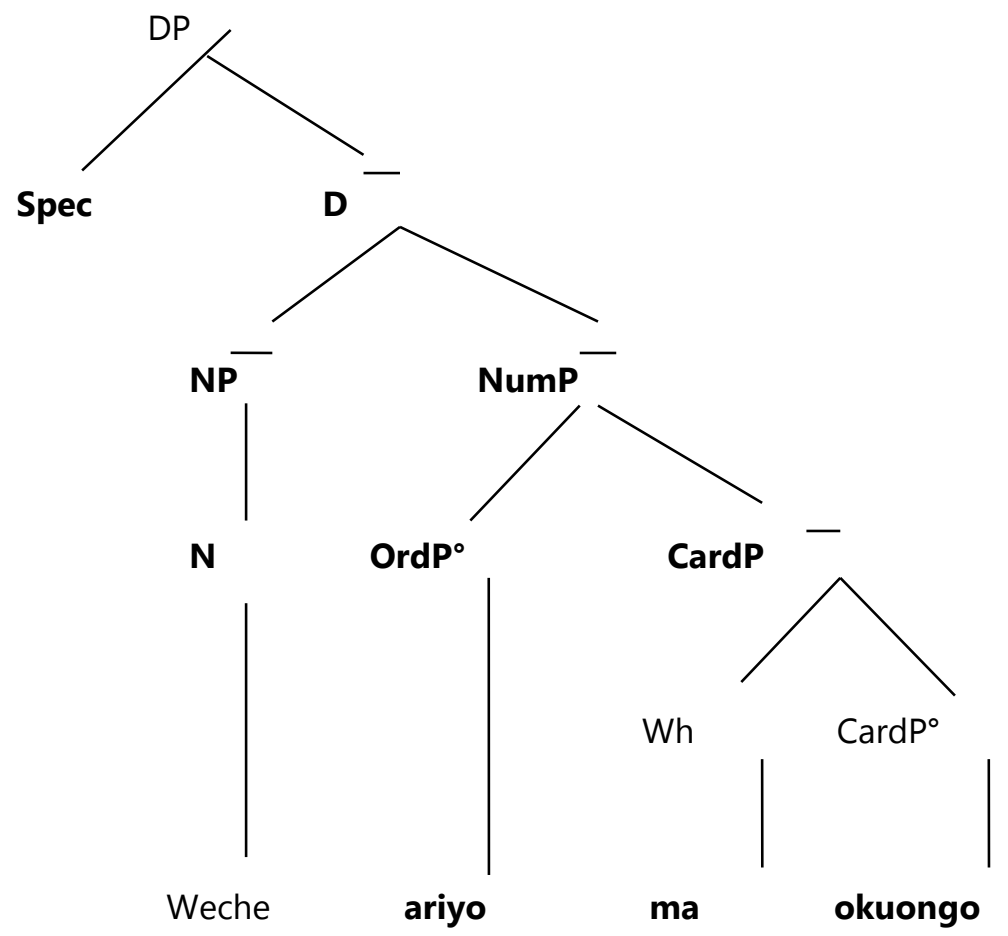

Fig. 14 Projection of NumP 


\section{Relative clauses}

Abdoulaye (2011), notes that relative clauses, just like PPs and APs, give more information about nouns and can be adjoined to nouns. Relative clause however, has a functional word which connects it to another part of the sentence (relative pronoun). Relative clause is adjoined to the DP. Mose (2012), points that they are adjoined to NP within the DP. Tamanji (2000) on the other hand points out that they are adjoined to the DP. In Dholuo, they occur at the final position of the DP. Relative clauses in Dholuo is introduced by relative pronouns such as mane (which) referring to an object and ng'a (who) referring to people. An example of a R.cl in a Dholuo DP can be illustrated with example 15 below.

Dholuo

Gloss

15. Buk manitie ei bag Book which is inside bag The book which is inside the bag

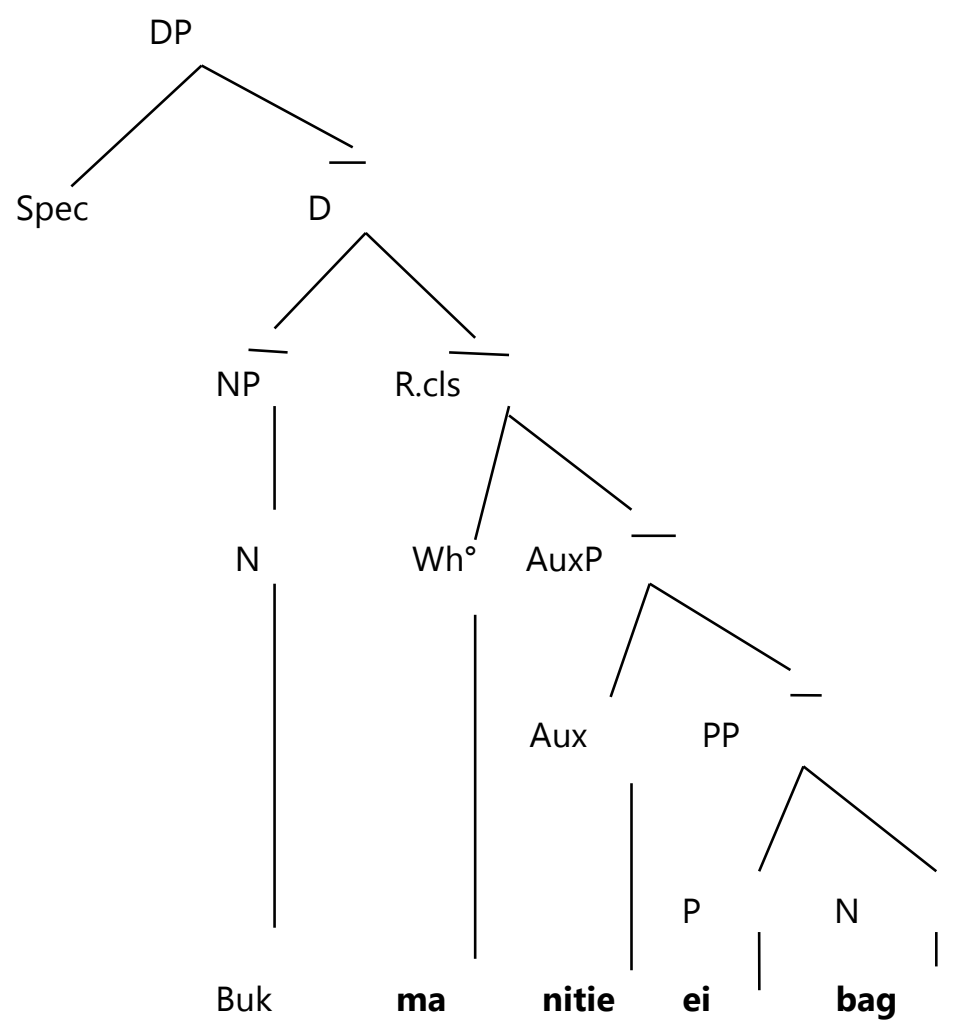

Fig. 15 Projection of R.cls using X-bar schema

\section{Conclusion}

Abney (1987), states that the primary property of functional elements is that they select a unique complement, which is not plausible as either an argument or an adjunct of functional elements. This paper realized that in Dholuo DP, functional heads (elements) select NP as their complements. The functional heads identified were: Demonstratives, possessives and quantifiers majorly, others were: Articles, indefinite pronouns, auxiliary verbs and relative clauses. These elements are post-nominal however, demonstratives were found to be both prenominal and post-nominal. Pre-nominal demonstratives have pragmatic meaning e.g. 'ma wuoi' (this is a boy) and post-nominal demonstrative have locative meaning e.g. 'wuoi ni' (this boy). Relative clauses contain relative words, verbs and adjectives. 
References

Abney, S. (1987). The English noun phrase in its sentential aspect. PhD dissertation. MIT Press.

Adger, D. (2003). Core syntax. Oxford: Oxford University Press.

Arlotta. (1972). Introduction to historical linguistics. New York: Houghton

Benard, O. Florence, I and Sangai, M. (2013). Exposition of adopted lexemes in Dholuo. Linguistics And literature studies 1(1): 46-53, 2013. Maseno University, Kenya

Bernstein, J. B. (1993). Topics in the syntax of nominal structure across Romance. Doctoral dissertation The City University of New York (2008).

Reformulating the determiner phrase analysis. Language and linguistics compass 2, 1-25.

Carnie, Andrew (2007). Syntax: a generative introduction. $2^{\text {nd }}$ edition. Oxford: Blackwell Publishers.

Chomsky, N. (1957). Syntactic structures. The Hague: Mouton.

Eunita, D. (2006). Selected proceedings of the $36^{\text {th }}$ annual Conference of African linguistics. University of South Carolina.

Flick, U. (2006). An introduction to qualitative research. London: Sage Publications Ltd.

Fucui, N. (1995). Theory of projection in syntax. Stanford: CSLI Publications.

Givon, T. (2001). Syntax: an introduction. (Vol.2). Amsterdam: John Benjamin.

Giusti, G.V (1997). The categorical status of determiners. In L. Haegeman (Eds.). The new comparative syntax. London and New York: Longman. Pp 95-123.

Gray, E. (2009). Doing research in the real world (2nded). London: Sage Publications. 